\title{
Subjective social status predicts long-term smoking abstinence
}

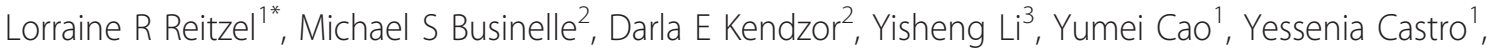 \\ Carlos A Mazas', Ludmila Cofta-Woerpel ${ }^{4}$, Paul M Cinciripini ${ }^{4}$, David W Wetter ${ }^{1}$
}

\begin{abstract}
Background: The relationship between subjective social status (SSS), a person's perception of his/her relative position in the social hierarchy, and the ability to achieve long-term smoking abstinence during a specific quit attempt is unknown. The purpose of this study was to examine the relationship between SSS and long-term smoking abstinence among 421 racially/ethnically diverse smokers undergoing a specific quit attempt, as well as the interactive effects of race/ethnicity and sex.
\end{abstract}

Methods: The main effects and moderated relationships of SSS on biochemically-confirmed, continuous smoking abstinence through 26 weeks post-quit were examined using continuation ratio logit models adjusted for sociodemographics and smoking characteristics.

Results: Even after adjusting for the influence of socioeconomic status and other covariates, smokers endorsing lower SSS were significantly less likely to maintain long-term smoking abstinence during a specific quit attempt than those with higher SSS (OR $=1.14,95 \% \mathrm{Cl}: 1.00-1.28 ; p=0.044)$. The statistical significance of this relationship, however, did not vary by race/ethnicity or sex.

Conclusions: SSS independently predicts long-term smoking abstinence during a specific quit attempt. SSS may be a useful screener to identify smokers at elevated risk of relapse who may require additional attention to facilitate long-term abstinence. More research is needed to understand the mechanisms underlying the relationship between SSS and long-term smoking abstinence in order to appropriately tailor treatment to facilitate abstinence among lower SSS smokers.

\section{Background}

Subjective Social Status (SSS) refers to the selfperception of one's status in the social hierarchy [1]. In general, those with greater financial resources typically endorse higher SSS. However, determinants of SSS extend beyond objective socioeconomic status (SES) indicators (such as income, education, and occupational status) to include satisfaction with financial resources, social trust, beliefs about upcoming opportunities, acculturation, and the anticipation of future security [2]. Although highly correlated with SES, several studies have indicated that SSS contributes unique variance in the prediction of self-rated health $[3,4]$, health indicators [5], depression [4], negative affect [6], and health

\footnotetext{
* Correspondence: Irreitze@mdanderson.org

'Department of Health Disparities Research, University of Texas MD

Anderson Cancer Center, Houston, TX, USA

Full list of author information is available at the end of the article
}

behaviors (e.g., fruit and vegetable consumption [7]). Most recently, research has shown that after adjusting for the effects of SES, higher SSS predicted greater rates of short-term smoking abstinence (i.e., through 2 weeks post-quit) during a smoking quit attempt [8]. Whether SSS predicts longer-term abstinence, however, is yet unknown. As smoking is becoming increasingly concentrated among individuals of low SES, incremental predictors of smoking cessation are useful to identify higher risk subgroups of smokers who may need more intensive interventions to successfully quit smoking.

SSS may represent an incremental predictor of various health-related outcomes over traditional indicators of SES because it captures the nuances of SES that might affect social standing (e.g., quality of education, prestige associated with a particular workplace, personal control in a particular job), taps into rarely assessed SES components (i.e., wealth), and captures the experience of 
societal inequalities and inequities $[1,2,9,10]$. These unique components of SSS may affect health-related outcomes through their associations with psychological distress (e.g., stress, depression) and physiologic dysfunction (in the case of low SSS) or psychological and physiological wellness (in the case of high SSS) [11]. They may also be particularly relevant to racial/ethnic minority groups or other segments of the population (e.g., women) that experience discrimination. Because these unique SSS components and their effects on the mechanisms underlying health-related outcomes may vary based on race/ethnicity and/or sex, the strength of the associations between SSS and health-related outcomes might also vary by race/ethnicity and/or sex. Indeed, racial/ethnic and gender differences have been cited in previous studies investigating associations between SSS and health outcomes [3,4,9]. However, although race/ethnicity and/or sex may moderate some SSS-health relationships, whether race/ethnicity and/or sex affect the relationship between SSS and smoking abstinence during a quit attempt is unknown. For a number of decades, smoking has remained the leading cause of preventable death and disability in the United States (U.S.) [12], and a clearer understanding of the factors predicting smoking cessation among historically understudied and underserved groups (e.g., racial/ethnic minorities, women) may facilitate the targeting of interventions to increase cessation rates, and help to identify groups in need of more intense interventions to quit smoking.

The purpose of this study was to examine the independent effect of SSS on long-term smoking abstinence during a specific quit attempt, while controlling for race/ethnicity, sex, SES, age, partner status, pre-quit smoking rate, and the number of years smoked. A complementary aim was to explore whether the relationship between SSS and long-term abstinence differed by race/ ethnicity and/or sex. This study represents an extension of our earlier work linking SSS with short-term smoking abstinence (through 2 weeks post-quit) [8] to examine the effects of SSS on long-term smoking abstinence (through 26 weeks post-quit).

\section{Methods}

\section{Procedures}

Data for the current study were collected in Houston, Texas, as part of a longitudinal, cohort study designed to examine social disparities in smoking cessation [13], which was approved by the Institutional Review Board of The University of Texas MD Anderson Cancer Center. Houston is currently the $4^{\text {th }}$ largest city in the U.S. and the most populous of Texas' metropolitan statistical areas. The enrollment period for this study was from April 2005 - April 2007. Recruitment was via local print and radio advertisements. Inclusion criteria included: $\geq 21$ years of age, daily smoker ( $\geq 5$ cigarettes per day for the last year), motivated to quit in $\leq 30$ days, and $\geq 6^{\text {th }}$ grade English proficiency. Potential participants were excluded if the nicotine patch was contraindicated, they reported use of tobacco products other than cigarettes, or they reported participation in a smoking cessation program within the past 90 days. Data for the current study were collected one week before quitting (baseline) and post-quit weeks $1,2,4$, and 26.

\section{Participants}

The parent study enrolled 424 racially/ethnically diverse participants. Sample size for the parent study was based on $80 \%$ power to detect a .25 standard deviation difference on questionnaire measures between any two racial/ ethnic groups at any single point in time. All participants received standard smoking cessation treatment including six weeks of nicotine patch therapy, six brief smoking cessation counseling sessions based on the Treating Tobacco Use and Dependence Clinical Practice Guideline, [14] and self-help materials. Three participants in the parent study failed to answer the SSS item and were excluded from this study.

\section{Measures}

All measures in this study were administered and completed via computer.

\section{Sociodemographic and Smoking Characteristics}

Sociodemographic and smoking characteristics were measured at baseline and included race/ethnicity, sex, SES, age, partner status, pre-quit smoking rate (the number of cigarettes smoked per day), and the number of years smoked. Race/ethnicity was self-reported as: non-Latino White, non-Latino Black, or Latino. SES was represented by three variables: annual household income, educational level, and employment status. Categories of income were: $<\$ 20,000$ a year or $\geq \$ 20,000$. Categories of education were: < high school education, high school education (or GED), some college (no degree), or college degree. Categories of employment were: employed or not employed. Partner status categories were: married or living with partner versus other.

\section{Subjective Social Status}

Subjective social status was measured at baseline with the SES version of the MacArthur Scale of Subjective Social Status, developed by the John D. and Catherine T. MacArthur Research Network on Socioeconomic Status and Health [15]. This measure presents a 10-rung ladder to the participant with instructions to imagine that it represents where people stand in society, with higher rungs representing higher status (i.e., more 
money, more education, and better jobs) [1]. Participants are asked to select the rung that best represents where they think they stand relative to others in the U.S., resulting in a continuous variable ranging from 1 to 10 .

\section{Smoking Abstinence}

Continuous abstinence from smoking was defined as a self-report of abstinence from smoking since the quit date (not even a puff), which was verified by expired carbon monoxide levels of $\leq 10 \mathrm{ppm}$. Smoking status was assessed at weeks $1,2,4$, and 26 post-quit. Because the focus was on continuous abstinence, relapse at any post-quit week resulted in classification as relapsed from that point forward. The percentage of participants with missing smoking status was $18.7 \%$ at week $1,16.1 \%$ at week $2,14.3 \%$ at week 4 , and $14.5 \%$ at week 26 . An intention-to-treat procedure was followed, whereby participants with missing smoking status were considered not abstinent (i.e., relapsed).

\section{Data Analysis}

All analyses were performed using Statistical Analysis Software (version 9.1). Preliminary analyses explored differences in sociodemographic and smoking characteristics by race/ethnicity and sex using Chi-Square tests for categorical variables and Analyses of Variance for continuous variables. Primary analyses examined the relationship between SSS and long-term abstinence. Because continuous abstinence was the outcome, continuation ratio (CR) logit models (SAS PROC GENMOD; [16-19]) were used to examine the influence of SSS on abstinence across weeks $1,2,4$, and 26 post-quit. CR logit models are appropriate when ordered categories (e.g., relapsed at week 1 , abstinent at week 1 but relapsed at week 2 , abstinent at week 2 but relapsed at week 4 , abstinent at week 4 but relapsed at week 26 , and abstinent through week 26) represent a progression through stages [16-18]. The CR logit models operate by modeling the conditional probability of being abstinent at the current assessment point given that a participant has been abstinent through the most recent assessment point. Analyses adjusted for stage only were followed by analyses adjusted for stage and the following covariates: race/ethnicity, sex, SES, age, partner status, pre-quit smoking rate, and the number of years smoked. These covariates were selected based on their established relationships with smoking relapse (for example, see [20-22]), and included in order to isolate the effect of subjective social status on long-term, continuous abstinence over and above the effects of these variables. Next, additional adjusted CR models were used to examine whether race/ethnicity or sex (respectively) were potential moderators of the effect of SSS on longterm smoking abstinence.

\section{Results}

\section{Sample Characteristics}

Participants $(N=421,46 \%$ male) were $33 \%$ non-Latino White $(n=137), 34 \%$ non-Latino Black $(n=144)$, and $33 \%$ Latino $(n=140)$. They were 41.2 years of age on average $(S D=11.2$, median $=42$, range $21-73)$, and $34 \%$ reported being married or living with a partner. With regard to SES variables, 38\% of respondents reported less than $\$ 20,000$ in annual household income, $14 \%$ lacked a high school diploma or equivalency, and $42 \%$ reported current unemployment. At baseline, participants smoked an average of $21.1(S D=10.3)$ cigarettes per day for an average of 21.6 years $(S D=11.1)$.

\section{Preliminary Analyses}

Racial/ethnic groups were examined for significant differences on sociodemographics and smoking characteristics at baseline (Table 1). Results indicated that White participants smoked more cigarettes per day than both Black and Latino participants, and both Black and White participants smoked for more years than Latinos. Latinos were younger than the Black and White groups in this sample and more likely than the other racial/ethnic groups to be male, employed, and earning $\$ 20,000$ or more in annual household income. Of all racial/ ethnic groups, Black participants had the highest unemployment rates and the highest proportion of individuals earning less than $\$ 20,000$ annually. There were no significant differences between racial/ethnic groups on SSS.

Sex groups were also examined for significant differences on sociodemographics and smoking characteristics at baseline (Table 2). Results indicated that women smoked fewer cigarettes per day than men prior to quitting. Notably, women were significantly more likely to endorse an annual household income of less than $\$ 20,000$ and to be unemployed. Women also endorsed lower SSS than men.

\section{Primary Analyses}

In unadjusted analyses, SSS predicted long-term smoking abstinence $\left[\beta=.20, \mathrm{SE}=.05 ; \chi^{2}(1)=14.83\right.$; OR $=$ 1.23 (95\% CI: 1.11-1.36); $p=.0001]$. In analyses controlling for race/ethnicity, sex, SES, age, partner status, pre-quit smoking rate, and the number of years smoked, SSS remained a significant predictor of long-term smoking abstinence $\left[\beta=.13, \mathrm{SE}=.06 ; \chi^{2}(1)=4.07\right.$; OR $=$ 1.14, 95\% CI: $1.00-1.28$; $p=.044$; Table 3$]$. The SSS by stage interaction was not significant, indicating that the effect of SSS on abstinence was consistent across postquit weeks 1,2 , 4, and 26 ( $p=.145)$. 
Table 1 Participants' Characteristics at Baseline by Race/Ethnicity

\begin{tabular}{|c|c|c|c|c|}
\hline & White $n=137$ & Black $n=144$ & Latino $n=140$ & \\
\hline & n [\%] or mean $( \pm S D)$ & $\mathrm{n}[\%]$ or mean $( \pm \mathrm{SD})$ & n [\%] or mean $( \pm S D)$ & $p$ value \\
\hline \multicolumn{5}{|l|}{ Demographics } \\
\hline Sex & & & & 0.022 \\
\hline Female & 78 [56.9] & $86[59.7]$ & $62[44.3]$ & \\
\hline Male & $59[43.1]$ & $58[40.3]$ & $78[55.7]$ & \\
\hline Age & $42.9( \pm 11.7)$ & $44.8( \pm 9.9)$ & $36( \pm 10.2)$ & $<0.001$ \\
\hline Partner Status & & & & $<0.001$ \\
\hline Married/living with partner & $42[30.9]$ & $35[24.5]$ & $67[48.6]$ & \\
\hline Other (e.g., single) & 94 [69.1] & $108[75.5]$ & $71[51.4]$ & \\
\hline \multicolumn{5}{|l|}{ Socioeconomic Status } \\
\hline Annual Household Income & & & & $<0.001$ \\
\hline$<20,000$ & $47[39.2]$ & $76[57.1]$ & $35[29.4]$ & \\
\hline$\geq 20,000$ & $73[60.8]$ & 57 [42.9] & $84[70.6]$ & \\
\hline Educational Level & & & & 0.009 \\
\hline$<$ High school & 14 [10.3] & 17 [11.9] & 27 [19.6] & \\
\hline High school/GED & 29 [21.3] & 29 [34.3] & $42[30.4]$ & \\
\hline Some college (no degree) & $43[31.6]$ & $44[30.8]$ & $41[29.7]$ & \\
\hline College degree & $50[36.8]$ & 33 [23.0] & 28 [20.3] & \\
\hline Employment Status & & & & $<0.001$ \\
\hline Employed & $71[52.6]$ & 68 [47.9] & $101[73.0]$ & \\
\hline Unemployed & $64[47.4]$ & $74[52.1]$ & 37 [26.8] & \\
\hline \multicolumn{5}{|l|}{ Smoking Characteristics } \\
\hline Average number of CPD & $23.4( \pm 9.1)$ & $20.9( \pm 12.0)$ & $19( \pm 9.0)$ & 0.001 \\
\hline Number of years smoked & $23.2( \pm 11.8)$ & $23.5( \pm 11.3)$ & $18( \pm 9.3)$ & $<0.001$ \\
\hline Social Status Ladder & $6.0( \pm 1.9)$ & $5.8( \pm 1.7)$ & $6.0( \pm 1.8)$ & 0.507 \\
\hline
\end{tabular}

Note: $\mathrm{CPD}=$ Self-reported number of cigarettes smoked per day at baseline. GED = General Equivalency Diploma.

\section{Moderator Analyses}

The relationship between SSS and long-term abstinence was not moderated by race/ethnicity or sex in unadjusted [race/ethnicity: $\chi^{2}(2)=1.94, p=.379$; sex: $\chi^{2}$ $(1)=0.28, p=.597$ ] or adjusted [race/ethnicity: $\chi^{2}(2)=$ $0.56, p=.755$; sex: $\left.\chi^{2}(2)=0.01, p=.924\right]$ analyses.

\section{Discussion}

The purpose of this study was to examine whether SSS predicted long-term smoking abstinence (through 26 weeks post-quit) among a racially/ethnically diverse sample of smokers undergoing a specific quit attempt. The results demonstrated that SSS conveys unique predictive information with respect to long-term smoking abstinence, with higher SSS being associated with a greater likelihood of maintaining abstinence over time. While there have been a number of cross-sectional studies linking SSS with self-rated health and health indicators, few studies have used a longitudinal design and even fewer have done so in the examination of the effect of SSS on health behaviors. The current research builds on our previous work demonstrating that SSS predicted short-term smoking abstinence in this racially/ethnically diverse sample [8], and suggests that quitting smokers endorsing lower SSS may face significant hurdles in maintaining both short- and long-term abstinence. These results add to a growing body of literature documenting that SSS contributes to the prediction of selfrated health $[3,4]$, health indicators [4-6], and health behaviors [7] over and above the influence of objective SES indicators.

A secondary aim of this study was to assess whether race/ethnicity and/or sex moderated the relationship between SSS and long-term smoking abstinence. Although previous studies have supported that relationships between SSS and health-related outcomes are moderated by race/ethnicity and sex $[3,4,9]$, this study failed to support the moderating effects of these variables on the relationship between SSS and long-term smoking abstinence. One possible explanation for this finding is that the unique factors that SSS captures over SES are common to all population groups examined, and therefore affected smoking abstinence equally among these groups. However, this may be unlikely given prior research indicating that determinants of SSS differ by race/ethnicity and sex [3,4,9] and, in some cases, may be relevant only to certain racial/ethnic groups (e.g., acculturation [23]). Therefore, another 
Table 2 Participants' Characteristics at Baseline by Sex

\begin{tabular}{lccc}
\hline & Men $\mathrm{n}=195$ & Women $\mathrm{n}=226$ & \\
\hline & $\begin{array}{c}\mathrm{n}[\%] \text { or mean } \\
( \pm \text { SD })\end{array}$ & $\begin{array}{c}\mathrm{n}[\%] \text { or mean } \\
( \pm \text { SD) }\end{array}$ & $\begin{array}{c}p \\
\text { value }\end{array}$ \\
\hline $\begin{array}{l}\text { Demographics } \\
\text { Race/ethnicity }\end{array}$ & & & \\
$\quad$ Non-Latino White & $59[30.0]$ & $78[34.5]$ & \\
$\quad$ Non-Latino Black & $58[29.7]$ & $86[38.1]$ & \\
$\quad$ Latino & $78[40.0]$ & $62[27.4]$ & \\
Age & $41.2( \pm 11.3)$ & $42.3( \pm 11.2)$ & 0.888 \\
Partner Status & & & 0.212 \\
$\quad$ Married/living with & $72[37.7]$ & $72[31.9]$ & \\
$\quad$ partner & & & \\
$\quad$ Other (e.g., single) & $119[62.3]$ & $154[68.1]$ & \\
\hline
\end{tabular}

\begin{tabular}{lccc}
\hline $\begin{array}{l}\text { Socioeconomic Status } \\
\text { Annual Household }\end{array}$ & & \\
$\begin{array}{l}\text { Income } \\
\quad<20,000\end{array}$ & $65[37.4]$ & $93[47.0]$ & \\
$\quad 220,000$ & $109[62.6]$ & $105[53.0]$ & \\
$\begin{array}{l}\text { Educational Level } \\
\quad<\text { High school }\end{array}$ & $27[14.1]$ & $31[13.7]$ & 0.433 \\
$\quad$ High school/GED & $62[32.5]$ & $58[25.6]$ & \\
$\quad \begin{array}{l}\text { Some college (no } \\
\text { degree) }\end{array}$ & $56[29.3]$ & $72[31.9]$ & \\
$\quad$ College degree & $46[24.1]$ & $65[28.8]$ & \\
Employment Status & & & 0.005 \\
$\quad$ Employed & $124[65.3]$ & $116[51.6]$ & \\
$\quad$ Unemployed & $66[34.7]$ & $109[48.4]$ & \\
\hline
\end{tabular}

\section{Smoking}

Characteristics

\begin{tabular}{lccc} 
Average number of CPD & $23.1( \pm 11.8)$ & $19.4( \pm 8.4)$ & $<0.001$ \\
Number of years smoked & $21.9( \pm 11.1)$ & $21.3( \pm 11.2)$ & 0.627 \\
\hline Social Status Ladder & $6.1( \pm 1.7)$ & $5.7( \pm 1.8)$ & 0.018 \\
\hline
\end{tabular}

Note: CPD = Self-reported number of cigarettes smoked per day at baseline. $\mathrm{GED}=$ General Equivalency Degree.

explanation might be that the unique components of SSS, although varying in significance and weighted differently between race/ethnicities and the sexes, have a similar effect on the mechanisms underlying smoking cessation. Many studies have confirmed the role of depression, negative affect, and stress in smoking relapse (e.g., [24-27]), and it may be that these are the mechanisms through which SSS uniquely predicts smoking abstinence among all racial/ethnic and sex groups. This supposition is partially supported by previous research finding that depression mediated the relationship between SSS and short-term smoking abstinence [8]. However, a post-hoc analysis indicated that further adjusting our models for baseline depressive symptoms as measured by the Center for Epidemiologic Studies Depression Scale [28] did not alter the pattern of results. A better understanding of the mechanisms underlying the relationship between SSS and smoking cessation, and how these may vary over the course of the quit attempt, is needed.

Strengths of this study include the longitudinal design and the use of a racially/ethnically diverse sample of participants. Because smoking is the leading cause of morbidity and mortality in the U.S. and is a major contributor to health disparities [12], enhancing understanding of the predictors of smoking abstinence is vital to the development of interventions and the targeting of treatment to affected groups. Results of the current study clearly demonstrate that smokers endorsing lower SSS are at increased risk of relapse during a smoking quit attempt as compared with smokers endorsing higher SSS scores. Results also suggest that individuals endorsing lower SSS might benefit from targeted interventions to help facilitate smoking cessation. Whether such targeted interventions might include a more intense (e.g., greater coverage of issues) or higher dosage (e.g., increased number of sessions) intervention for smoking cessation than standard treatment is fodder for future research. However, the standard smoking cessation intervention provided to all participants in this study (i.e., brief counseling, self-help materials, and the "patch") was not sufficient to enable cessation among lower SSS smokers in this study. As the SSS scale is a relatively quick and easy tool to administer [15], smoking cessation programs could use it as a screener for smokers who may require additional attention to facilitate abstinence, although more information is needed on what might constitute a meaningful SSS cut-off for additional service provision. Future research should explore how to better treat lower SSS smokers, which would benefit from a greater understanding of the mechanisms driving the relationship between SSS and smoking abstinence.

Another potential application of this finding could entail the development of interventions designed to facilitate smoking cessation while also affecting the perceived social status of lower SSS individuals. This is a completely unexplored area but might entail building social trust $[2,10]$ by encouraging involvement in community or church activities, enhancing social standing through the adoption of community leadership roles (e.g., homeowners association board, neighborhood watch), or facilitating hope for the future by assisting in the identification and utilization of local resources (e.g., job placement agencies, food banks, reduced-rate health care options). It is unknown whether such interventions might affect SSS and facilitate smoking cessation, but these possibilities could be examined in future research.

Limitations of the current study include the potential for limited power to detect interaction effects, as the parent study was not specifically designed to explore moderators of SSS effects on long-term cessation. 
Table 3 Results of Unadjusted and Adjusted Models for Subjective Social Status Predicting Smoking Abstinence

\begin{tabular}{|c|c|c|}
\hline Variables in Unadjusted Model & OR & $95 \% \mathrm{Cl}$ \\
\hline Social Status Ladder & 1.23 & $1.11-1.36$ \\
\hline Variables in Adjusted Model & OR & $95 \% \mathrm{Cl}$ \\
\hline \multicolumn{3}{|l|}{ Race/ethnicity } \\
\hline Non-Latino White & 1 & \\
\hline Non-Latino Black & 0.90 & $0.54-1.53$ \\
\hline Latino & 0.98 & $0.58-1.67$ \\
\hline \multicolumn{3}{|l|}{ Sex } \\
\hline Male & 1 & \\
\hline Female & 1.09 & $0.73-1.64$ \\
\hline Age & 1.04 & $1.01-1.07$ \\
\hline \multicolumn{3}{|l|}{ Partner Status } \\
\hline Married or living with partner & 1 & \\
\hline Other (e.g., single) & 0.82 & $.053-1.28$ \\
\hline \multicolumn{3}{|l|}{ Annual Household Income } \\
\hline$<20,000$ & 0.79 & $0.48-1.31$ \\
\hline$\geq 20,000$ & 1 & \\
\hline \multicolumn{3}{|l|}{ Education Level } \\
\hline$<$ High school & 1 & \\
\hline High school/GED & 1.00 & $0.51-1.97$ \\
\hline Some college (no degree) & 1.20 & $0.63-2.30$ \\
\hline College degree & 0.97 & $0.49-1.91$ \\
\hline \multicolumn{3}{|l|}{ Employment Status } \\
\hline Employed & 1 & \\
\hline Unemployed & 0.51 & $0.31-0.85$ \\
\hline Average number of CPD & 1.01 & $0.98-1.03$ \\
\hline Number of years smoked & 0.99 & $0.97-1.02$ \\
\hline Social Status Ladder & 1.14 & $1.00-1.28$ \\
\hline
\end{tabular}

Note: $\mathrm{OR}=$ Odds Ratio. CPD = Self-reported number of cigarettes smoked per day at baseline. GED = General Equivalency Degree. Both unadjusted and adjusted models controlled for stage.

Future studies should replicate these analyses with a more purposeful design. Future studies in this area might also adjust for other SES variables not collected (e.g., wealth) in the present study in order to further isolate the unique effects of SSS on health indicators and outcomes. Also, participants in this study were selfselected, treatment-seeking smokers who may differ from smokers who attempt to quit without treatment in important ways, and the influence of SSS on cessation among the latter group remains unknown. It is also worthy of note that this study relied on self-report of racial/ethnic group membership, which may not perfectly align with biologically-based classifications of race/ethnicity. Also, the parent study was designed to recruit Whites, Blacks and Latino smokers in equal proportions, which may not be representative of the local population in terms of racial/ethnic distribution or other factors. Thus, results may not generalize to the larger population of smokers in Houston. Importantly, our interpretation of the data assumes that the unique predictive ability of SSS over SES indicators is not based on measurement error. Although these assumptions have been supported in previous literature (e.g., $[1,29]$ ), we cannot rule out that the presence of unknown and unmeasured confounders might have influenced these results.

\section{Conclusions}

This study examined whether SSS predicted long-term abstinence from smoking during a specific quit attempt, and assessed potential moderation by racial/ethnic group or sex. Our results indicated that smokers endorsing higher SSS were more likely to maintain long-term smoking abstinence during a specific quit attempt than smokers with lower social status ratings, regardless of their race/ethnicity or sex. Although a number of studies have supported inverse relationships between SES indicators (e.g., income, education) and smoking cessation (cf. [13]), the current study indicates that SSS is an even stronger predictor. SSS, the self-reported perception of relative standing in the social hierarchy, captures SES but also taps into the experience of societal inequities and a person's feelings of hope about future status change $[1,10]$. It may be these, or other, unique components of SSS that are especially important influences on health and health behaviors. More research is needed to understand the mechanisms underlying the relationship between SSS and long-term smoking abstinence, and to appropriately tailor treatment to facilitate abstinence among smokers endorsing lower SSS.

\section{Acknowledgements}

This manuscript was supported by grants from the National Institute of Drug Abuse (R01DA014818 to DWW), the Centers for Disease Control and Prevention (K01DP001120 to LRR), and the National Institutes of Health through The University of Texas MD Anderson's Cancer Center Support Grant (CA016672). The content is solely the responsibility of the authors and does not necessarily represent the official views of the National Institute of Drug Abuse, the Centers for Disease Control and Prevention, or the National Institutes of Health. We are grateful for the various contributions of the research staff at The University of Texas MD Anderson Cancer Center who assisted with implementation of the original project.

\section{Author details}

'Department of Health Disparities Research, University of Texas MD Anderson Cancer Center, Houston, TX, USA. ${ }^{2}$ Division of Health Promotion and Behavioral Sciences, University of Texas School of Public Health, Dallas Regional Campus, Dallas, TX, USA. ${ }^{3}$ Department of Biostatistics, University of Texas MD Anderson Cancer Center, Houston, TX, USA. ${ }^{4}$ Department of Behavioral Science, University of Texas MD Anderson Cancer Center, Houston, TX, USA.

\section{Authors' contributions}

LRR, MSB, DEK, YCastro, and DWW conceptualized the research question and wrote the manuscript. $Y L$ and $Y C a o$ conducted the data analysis, interpreted results, and reviewed the data analysis and results sections. DWW is the senior author of the paper, and the principal investigator on the supporting grant (National Institute of Drug Abuse; R01DA014818). CAM, LC-W, and PMC helped with the conceptualization of the overall project and methodology, and reviewed and edited manuscript drafts. PMC is a co- 
investigator on the supporting grant. All authors have read, contributed to, and approved the final manuscript.

\section{Competing interests}

The authors do not have any competing interests directly pertaining to this work; however, we would like to report that PM Cinciripini has served on the scientific advisory board of Pfizer Pharmaceuticals and has conducted educational talks for physicians on smoking cessation that were sponsored by Pfizer within the past five years.

Received: 20 August 2010 Accepted: 25 February 2011

Published: 25 February 2011

\section{References}

1. Adler NE, Epel ES, Castellazzo G, Ickovics JR: Relationship of subjective and objective social status with psychological and physiological functioning: Preliminary data in healthy white women. Health Psychology 2000 19(6):586-592.

2. Franzini L, Fernandez-Esquer ME: The association of subjective social status and health in low-income Mexican-origin individuals in Texas. Soc Sci Med 2006, 63(3):788-804.

3. Ostrove JM, Adler NE, Kuppermann M, Washington AE: Objective and subjective assessments of socioeconomic status and their relationship to self-rated health in an ethnically diverse sample of pregnant women. Health Psychol 2000, 19(6):613-618.

4. Demakakos P, Nazroo J, Breeze E, Marmot M: Socioeconomic status and health: the role of subjective social status. Soc Sci Med 2008, 67(2):330-340.

5. Gianaros PJ, Horenstein JA, Cohen S, Matthews KA, Brown SM, Flory JD, Critchley HD, Manuck SB, Hariri AR: Perigenual anterior cingulate morphology covaries with perceived social standing. Soc Cogn Affect Neurosci 2007, 2(3):161-173.

6. Reitzel LR, Vidrine Jl, Li Y, Mullen PD, Velasquez MM, Cinciripini PM, CoftaWoerpel L, Greisinger A, Wetter DW: The influence of subjective social status on vulnerability to postpartum smoking among young pregnant women. Am J Public Health 2007, 97(8):1476-1482.

7. Ghaed SG, Gallo LC: Subjective social status, objective socioeconomic status, and cardiovascular risk in women. Health Psychol 2007, 26(6):668-674.

8. Reitzel LR, Mazas CA, Cofta-Woerpel L, Li Y, Cao Y, Businelle MS, Cinciripini PM, Wetter DW: Subjective Social Status Affects Smoking Abstinence During Acute Withdrawal Through Affective Mediators. Addiction 2010, 105:928-936.

9. Adler N, Singh-Manoux A, Schwartz J, Stewart J, Matthews K, Marmot MG: Social status and health: a comparison of British civil servants in Whitehall-II with European- and African-Americans in CARDIA. Soc SCi Med 2008, 66(5):1034-1045.

10. Singh-Manoux A, Adler NE, Marmot MG: Subjective social status: its determinants and its association with measures of ill-health in the Whitehall II study. Soc Sci Med 2003, 56(6):1321-1333.

11. Mendelson T, Thurston RC, Kubzansky LD: Affective and cardiovascular effects of experimentally-induced social status. Health Psychol 2008, 27(4):482-489.

12. USDHHS: The Health Consequences of Smoking: A Report of the Surgeon General. Atlanta, GA: U.S. Department of Health and Human Services; 2004 [http://www.surgeongeneral.gov/library/ smokingconsequences/], CDC. Available at $\leq$

13. Businelle MS, Kendzor DE, Reitzel LR, Costello TJ, Cofta-Woerpel L, Li Y Mazas CA, Vidrine Jl, Cinciripini PM, Greisinger AJ, Wetter DW: Mechanisms linking socioeconomic status to smoking cessation: A structural equation modeling approach. Health Psychol 2010, 29:262-273.

14. Fiore M, Bailey WC, Cohen SJ, Dorfman SF, Goldstein MG, Gritz ER, Heyman RB, Roberto Jean C, Kottke TE, Mecklenburg RE, Dolan Mullen P, Nett LM, Robinson L, Stitzer ML, Tommasello ACM, Villejo L, Wewers ME: Treating Tobacco Use and Dependence [Rockville, Md.]: U.S. Dept. of Health and Human Services, Public Health Service; 2000.

15. Adler N: Social Status Ladder. John D and Catherine T MacArthur Research Network on Socioeconomic Status and Health 2000 [http://www.macses.ucsf. edu/research/psychosocial/subjective.php], Available at.

16. Agresti A: Categorical Data Analysis. 2 edition. Hoboken, New Jersey: John Wiley \& Sons, Inc; 2002.
17. Bender R, Benner A: Calculating Ordinal Regression Models in SAS and SPlus. Biometrical J 2000, 42(677-699).

18. McGowan MJ: Ordinal Outcomes with the Continuation Ratio Model. Proceedings of the Northeast SAS Users Group Conference 2000.

19. Allison PD: Logistic Regression Using the SAS System: Theory and Application (pp. 151-159) Cary, N.C: SAS Institute, Inc. and Wiley; 2001.

20. Wetter DW, Kenford SL, Smith SS, Fiore MC, Jorenby DE, Baker TB: Gender differences in smoking cessation. J Consult Clin Psychol 1999, 67(4):555-562.

21. Wetter DW, Cofta-Gunn L, Irvin JE, Fouladi RT, Wright K, Daza P, Mazas C, Cinciripini PM, Gritz ER: What accounts for the association of education and smoking cessation? Prev Med 2005, 40(4):452-460.

22. Vidrine Jl, Reitzel LR, Wetter DW: Smoking and health disparities. Current Cardiovascular Risk Reports 2009, 3:403-408.

23. Reitzel LR, Mazas C, Cofta-Woerpel L, Vidrine Jl, Businelle MS, Kendzor DE, Li Y, Wetter DW: Acculturative and Neighborhood Influences on Subjective Social Status Among Spanish-Speaking Latino Immigrant Smokers. Soc Sci Med 2010, 70:677-683.

24. Shiffman S: Dynamic influences on smoking relapse process. J Pers 2005, 73(6):1715-1748

25. Shiffman S, Paty JA, Gnys M, Kassel JA, Hickcox M: First lapses to smoking: Within-subjects analysis of real-time reports. J Consult Clin Psychol 1996, 64(2):366-379.

26. Shiffman S, Waters AJ: Negative affect and smoking lapses: a prospective analysis. J Consult Clin Psychol 2004, 72(2):192-201.

27. Gwaltney CJ, Shiffman S, Sayette MA: Situational correlates of abstinence self-efficacy. J Abnorm Psychol 2005, 114(4):649-660.

28. Radloff $L$ : The CES-D Scale: A self-report depression scale for research in the general population. Appl Psycho Measurement 1977, 1:385-401.

29. Operario D, Adler NE, Williams DR: Subjective social status: Reliability and predictive utility for global health. Psychol Health 2004, 19:237-246.

Pre-publication history

The pre-publication history for this paper can be accessed here: http://www.biomedcentral.com/1471-2458/11/135/prepub

doi:10.1186/1471-2458-11-135

Cite this article as: Reitzel et al:: Subjective social status predicts longterm smoking abstinence. BMC Public Health 2011 11:135.

\section{Submit your next manuscript to BioMed Central and take full advantage of:}

- Convenient online submission

- Thorough peer review

- No space constraints or color figure charges

- Immediate publication on acceptance

- Inclusion in PubMed, CAS, Scopus and Google Scholar

- Research which is freely available for redistribution

Submit your manuscript at www.biomedcentral.com/submit
C Biomed Central 